\title{
The Effect of 12 Weeks of Wrestling + Warm-Up Program on Functional Movement Screen Scores in Cadet Wrestlers
}

\author{
${ }^{1}$ Rasoul Bayati", ${ }^{1}$ Ali Shamsi Majelan, ${ }^{1}$ Bahman Mirzaei, ${ }^{2}$ Ioannis Barbas \\ ${ }^{1}$ Faculty of Sport Sciences, University of Guilan, Rasht, Iran. ${ }^{2}$ Democritus University of Thrace, \\ Komotini, Greece.
}

Submitted 25 October 2018; Accepted in final form 08 December 2018.

\begin{abstract}
Background. Wrestling is one of the most popular sports in the world. United World Wrestling have developed "Wrestling+" injury prevention program similar to the FIFA 11+. Objectives. the aim of the present study was to investigate the effect of 12 weeks of "Wrestling+" warm-up program on Functional Movement Screen scores in cadet wrestlers. Methods. The study population included all cadet wrestlers of Rasht city where 24 freestyle wrestlers were selected by the convenience sampling, and further divided into intervention $(n=12)$ and control $(n=12)$ groups. The intervention group performed "Wrestling+" warm-up program for 12 weeks and three times a week while the control group performed routine warm-up during the period of research. Functional Movement Screen tests including Deep Squat (DS), Hurdle Step (HS), In-Line Lunge (ILL), Shoulder Mobility (SM), Active Straight Leg Raise (ASLR), Trunk Stability Push Up (PU), and Rotary Stability (RS) were used in pre- and post-program. Results. There was a significant increase in the total Functional Movement Screen, DS, HS, ILL, PU scores, while there were no significant differences in SM, ASLR, and RS scores in intervention group. Also, there was a \%66.7 decrease in the number of wrestlers at high risk in Functional Movement Screen tests in the intervention group. There was no significant difference in any of the variables in the control group ( $\mathrm{p} \geq 0.05)$. Conclusion. The results of this study suggested that the "Wrestling+" warm-up program can improve the fundamental movement patterns and finally it may prevent the potential injuries.
\end{abstract}

\section{KEY WORDS: Injury Prevention, Fundamental Movement, Wrestle, Freestyle Wrestling, Injury Risk.}

\section{INTRODUCTION}

Wrestling is one of the most popular sports in the world and it is one of the first sport disciplines to be included in the program of the ancient Olympic Games (1). Freestyle and Greco-Roman are two wrestling styles that are practiced in the Olympics. Greco-Roman wrestling is a classic style involving upper body moves, while freestyle wrestling includes both upper and lower body moves (2). As with most sports, wrestling carries a risk of injury for wrestlers at both $=$ professional and amateur levels and across all ages and weight categories (3-
5). In a descriptive epidemiologic study, Shadgan et al. (2017) evaluated wrestling injuries during the 2016 Rio Olympic Games. In this study, 352 wrestlers sustained 22 injuries during 410 matches suggesting that the injury rate among wrestlers was 6.2 injuries per 100 athletes and 5.4 injuries per 100 matches which were lower than the figures in London 2012 (12\%) and Beijing 2008 (9.3\%) Olympic Games (6). The head/spine/trunk (24.5$48 \%$ ), upper extremity (9.3-42\%), lower extremity $(7.5-45.1 \%)$, and skin $(5-21.6 \%)$ are most

*. Corresponding Author:

Rasoul Bayati, MSc;

Faculty of Sport Sciences, University of Guilan, Rasht, Iran;

E-mail: bayatirasoul@gmail.com 
commonly injured sites in wrestling (7). All of these studies indicated that determining ways to lower the injury rate in wrestling should be a major focus and there is a need for programs to prevent injuries in this sport. Some parameters such as injury characteristics, injury mechanism, and information about the sport physical demands are important to design a proper injury prevention program (8). With this in mind, the injury prevention program "FIFA $11+$ " was developed by national and international experts under the leadership of the FIFA Medical and Research Centre (F-MARC) to reduce the incidence of football injuries, which has been validated in that sport (9). Similar to the FIFA 11+ program and according to the above-mentioned parameters, "Wrestling+" injury prevention program was developed in 2015 by UWW for wrestlers (10). Core stabilization, shoulder and leg strength, and balance training constitute the basis of "Wrestling+" injury prevention program. This program consists of 3 parts and 14 exercises. Implementation of proper techniques during all of the exercises is central to the program (8). Major clinical research studies have clearly indicated that consistent implementation of the FIFA 11+ can yield $30-50 \%$ reduction in the risk of injury in soccer (11). However, we do not have any study yet regarding the effects of "Wrestling+" warm-up program on reducing the injury risk in wrestlers. Musculoskeletal injury risk factors in intercollegiate athletes are divided into extrinsic risk factors such as footwear or playing surface, and intrinsic risk factors such as inadequate strength or high body mass index $(12,13)$. Identification of these risk factors by effective assessments and implementing injury prevention programs are crucial. Functional Movement Screen (FMS) developed by Cook (2006) is a popular assessment for evaluating modifiable risk factors in athletes, and it is a baseline assessment for fundamental movement capacity which challenges mobility, neuromuscular control, balance, and stability through seven fundamental movement patterns $(14,15)$. Due to the lack of evidence in this area, and given the importance of injury prevention in wrestling, the purpose of this study was to find the effect of 12 weeks of "Wrestling+" warm-up program on Functional Movement Screen scores in cadet wrestlers.

\section{MATERIALS AND METHODS}

Participants. The population of this study consisted of cadet wrestlers in Rasht city. Out of this population, 24 freestyle wrestlers were selected through available sampling and were divided into two the experimental (n: 12, age: $16.16 \pm 0.71$ years, height: $1.70 \pm 0.06 \mathrm{~m}$, weight: $68.50 \pm 3.19 \mathrm{~kg}$, body mass index: 23.67 $\pm 1.36 \mathrm{~kg} / \mathrm{m}^{2}$ ) and control (n: 12 , age: $16.41 \pm$ 0.79 years, height: $1.71 \pm 0.04$, weight: $66.33 \pm$ $4.11 \mathrm{~kg}$, body mass index: $22.65 \pm 1.75 \mathrm{~kg} / \mathrm{m}^{2}$ ) groups. The inclusion criteria in this study were having at least 1 year of regular exercise, not taking any medication, and not having any musculoskeletal injuries. All wrestlers read and signed the consent form.

Functional Movement Screen (FMS) Test. This test consisted of seven Deep Squat (DS), Hurdle Step (HS), In-Line Lunge (ILL), Shoulder Mobility (SM), Active Straight Leg Raise (ASLR), Trunk Stability Push Up (PU), and Rotary Stability (RS) movements. Score of 3 was given to those who performed the movement correctly and free of compensation and pain; score of 2 when the movement was performed with some level of compensation or incompletely; and score of 1 when the subject could not complete the movement. Eventually, zero was given when the subject experienced pain without any part of the movement done. The highest score of the three recorded attempts was used for analysis. In case of different scores on two sides (for movements assessed on both sides), the lower score between the two scores was recorded (16).

Wrestling+ Warm-up Program. This program has 3 parts and 14 exercises, which should be performed in a specific process (Figure 2). The key to this program is to use the correct method throughout all exercises and to pay full attention to correct posture and optimal control of the body. Part 1 involves performing slow-moving exercises with active shoulder stretches, grips, and bridges. Part 2 includes 5 exercises with a focus on core muscles, shoulder and leg strength, and balance, each of which consists of 3 levels with increasing difficulty. Finally, part 3 includes wrestling simulated exercises. Wrestlers begin with Level 1 exercises with the progression to the next level of the exercises being dependent on their performance of the previous stage with the duration and number of repetitions specified performed without difficulty (8). 


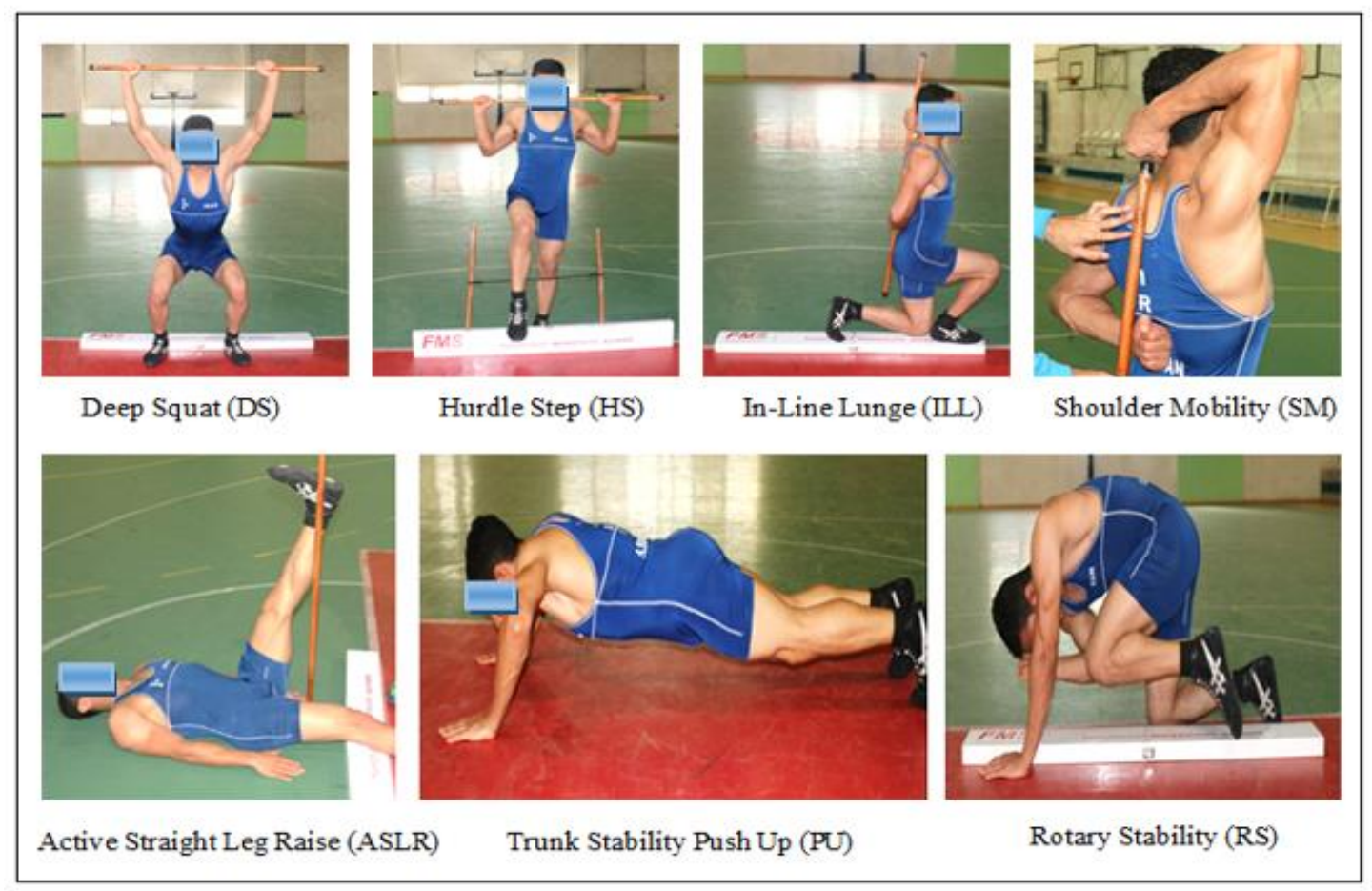

Figure 1. Functional Movement Screen.

In this research, wrestlers performed the first, second, and third levels of exercises for 3, 4, and 5 weeks, respectively each week three times (12 weeks and 36 sessions in total). Given the importance of proper implementation of the program movements and correcting them on due occasions, the instructor's presence and supervision were essential during the exercise.

Data collection. This research was a semiexperimental study which used pre- and post-test design with a control group. The independent variable of the study was 12 weeks of "Wrestling+" warm-up program while the dependent variable was the Functional Movement Screen test scores. Initially, all subjects took a 7part Functional Movement Screen test developed by Cook (2006). Then, the experimental group practiced in the "Wrestling+" warm-up program for 12 weeks while the control group completed their routine warm-up program within the same period of time. Once the program was completed, the Functional Movement Screen test was administered again for all subjects. All stages of the research were conducted at Rasht Wrestling House.
Statistical Analysis. In order to describe the data, descriptive statistics of mean and standard deviation were used, where repeated measurements ANOVA was employed to determine the effects of TIME and Group by SPSS software version 23 at a significant level of $\mathrm{p}<0.05$.

\section{RESULTS}

DS: The interaction effect of TIME*GROUP was significant $\left(\mathrm{F}_{2,1}=19.568 ; \mathrm{p}<0.001\right.$; Partial Eta squared $=0.471)$. Accordingly, there was no significant difference between the mean DS in the pre-test between the two groups. However, there was a significant difference between the two groups in the post-test in terms of the mean DS. However, there were no significant differences between the mean DS in the pre-test and post-test of the control group. On the other hand, in the experimental group there were significant differences between the mean DS in the pre-test and the post-test (pre-control = $1.67 \pm 00.49$, pre-experimental $=1.33 \pm 00.49$, postcontrol $=2.00 \pm 00.43$, post Experimental $=2.00 \pm$ 00.43) (Figure 3). 


\section{WRESTLING PLUS Warm Up Program}

2 or more times per week

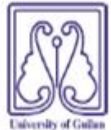

Part 1: Running, Grips, and Bridges (8 minutes)

1. Shoulder Rotations
Jog in place while rotating the
shoulders forward and
backward.
45 sec total

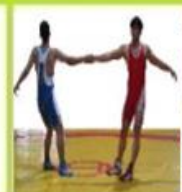

3. Pull each other

The athletes stand facing each other. They grasp their hands and attempt to pull each other. 45 sec each hand

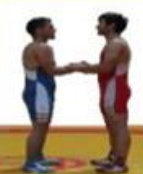

2. Grips

The athletes stand facing each other. They pull their partner's hands up the down. 45 sec each

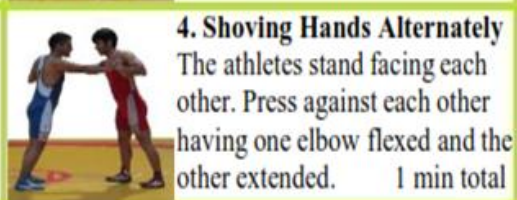

5. Neck

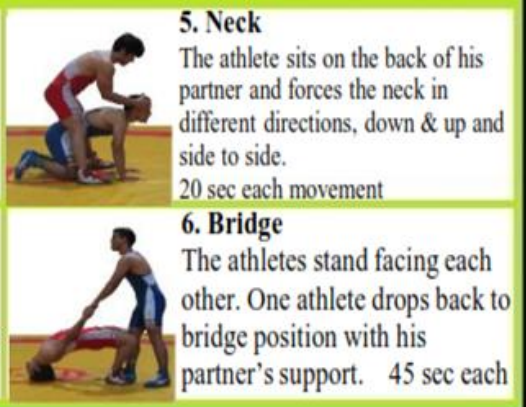

Part 2: Core, Leg Strength, and Balance (9 minutes) Level 1 Level 2 Level 3

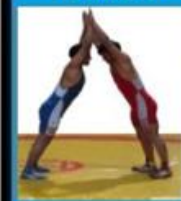

7. Shoving Hands

The athletes grasp their hands with ams bent. Both try to shove the hands extending their wrists over their heads. 2 sets -1 min each 8. Pulling

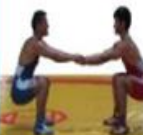

Grasp their hands with arm Extended and knees flexed 90 degrees. Try to flex their knees more and returm to original position. 2 sets -1 min each

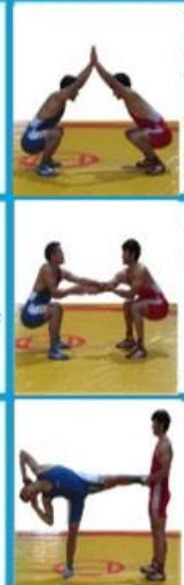

7. Shoving Hands in Squatting

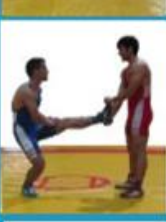

9. One Leg Stance

Hold one of your partner's legs straight while he tries to squat and straighten the other. 30 sec each leg

10. Combat with Raised Legs

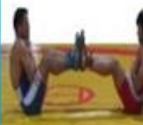

The athletes sit with legs slightly bent, soles touching. Push the partner. 2 sets -30 sec each

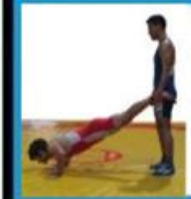

11. Push Ups

The athlete does push-ups while his partner hold his feet in the air. $45 \mathrm{sec}$ each

Position

The athletes try to shove the hands of the other while both bend knees and extend shoulders 2 sets -1 min each

8. Pulling Alternately Grasp their hands. Both alternately extended and flex the elbow. 2 sets -1 min each

\section{Shoving Fit-Ball}

9. One Leg-Side Rotation Rotate the standing leg to the side. Try to keep both legs straight while turning the body laterally.

30 sec each leg

10. Combat with Raised Legs Alternately

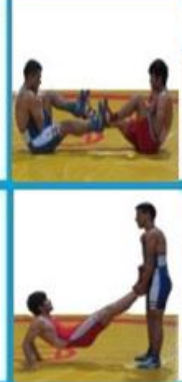

Push the part try to extend and flex the knees. 2 sets -30 sec each

\section{Push Ups-Supine}

The athlete does push-ups on supine position while his partner hold his feet in the air. 45 sec each

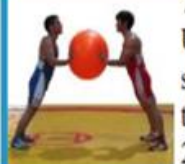

Using a fit-ball, both try to shove the fit-ball extending their wrists over their head. 2 sets -1 min each

8. Pulling in Bosu

The athletes stand on Bosu. Grasp their hands with arms extended and knees flexed 90 degrees. 2 sets -1 min each

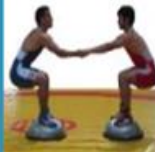
9. One Leg-Side Rotation on Bosu
Rotate the standing leg to the side. Rotate the standing leg to the side.
Try to keep both legs straight while turning the body laterally. 30 sec each leg

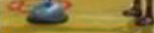

10. Combat with Raised Legs on Bosu

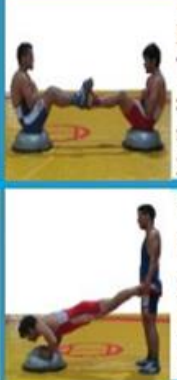

The athletes sit on Bosu. Their legs should be slightly bent, soles touching. Push the partner. 2 sets -30 sec each

\section{Part 3: Wrestling Simulation (3 minutes)}
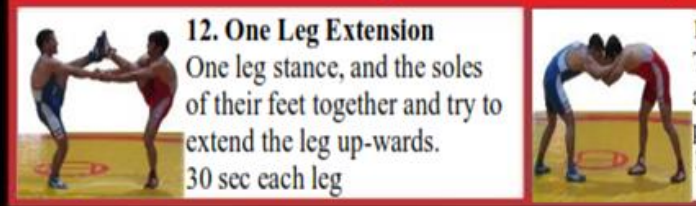

13. Standing Wrestling

The athletes stand facing each other and make wrestling movements (ie: pummel, fakes, hand fighting, etc , 1 min total

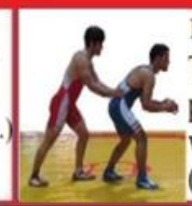

14. Pushing Wrestling

The athlete stands behind his partner and pushes him while he works to maintain position (stance) 30 sec each athlete

Figure 2. Wrestling+ warm-up program. 
HS: The interaction effect of TIME*GROUP was not significant $(\mathrm{F} 2,1=3.960 ; \mathrm{p}>0.059$; Partial Eta squared $=0.153)$. There was no significant difference between the mean HS in both the pre-test and post-test between the two groups. Again, there were no significant differences between the mean HS values in the pre-test and post-test of the control group. However, in the experimental group there were significant differences between the mean HS in the pre-test and the post-test (pre-control $=2.08 \pm$ 00.29 , pre-experimental $=1.91 \pm 00.29$, postcontrol $=2.25 \pm 00.45$, post-experimental $=2.58$ \pm 00.51 ) (Figure 4).

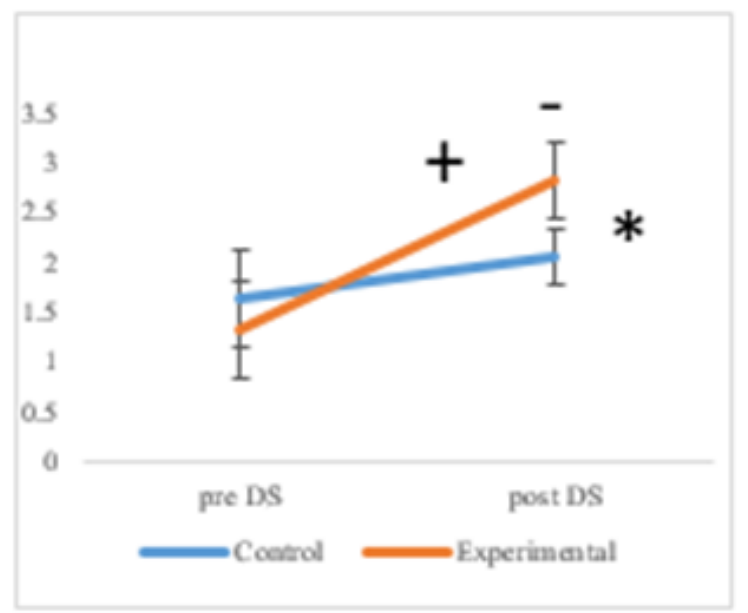

Figure 3. The Effects of Wrestling + warm-up program on Deep Squat (DS). *: interaction effect of GROUP*TIME is significant at $\mathrm{p}<0.05$. -: Significant difference with post-test in the two groups at $\mathrm{p}<0.05$. +: Significant difference with pre-test and post-test in the experimental and control groups at $\mathrm{p}<0.05$.

ILL: The interaction effect of TIME*GROUP was significant $(F 2,1=7.615$; $p<0.011$; Partial Eta squared $=0.257)$. There was, however, no significant difference between the mean ILL in the pre-test between the two groups. However, there was a significant difference between the two groups in the post-test in terms of the mean ILL. There were no significant differences between the mean ILL in the pre-test and posttest of the control group. However, in the experimental group there were significant differences between the mean ILL in the pre-test and the post-test (pre-control $=2.00 \pm 00.43$, pre-experimental $=1.92 \pm 00.29$, post-control $=$ $2.17 \pm 00.39$, post-experimental $=2.58 \pm 00.51$ ) (Fig. 5).

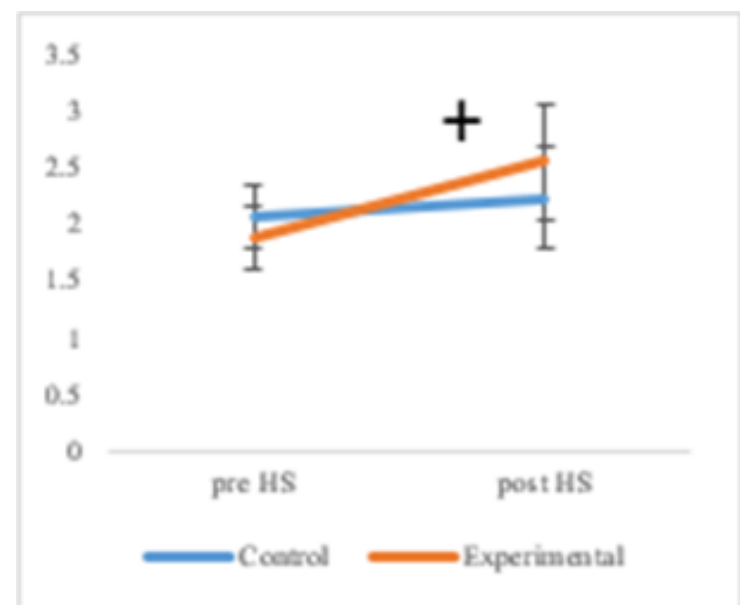

Figure 4. The Effects of Wrestling + warm-up program on Hurdle Step (HS). +: Significant difference with pre-test and post-test in the experimental and control groups at $\mathrm{p}<0.05$.

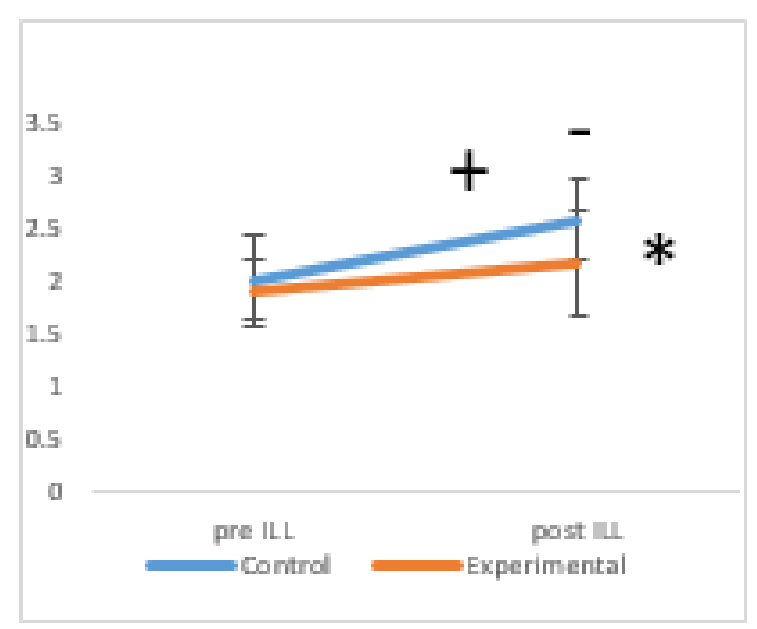

Figure 5. The Effects of Wrestling + warm-up program on In-Line Lunge (ILL). *: interaction effect of GROUP*TIME is significant at $p<0.05$. -: Significant difference with post-test in the two groups at $\mathrm{p}<0.05$. $+:$ Significant difference with pre-test and post-test in the experimental and control groups at $\mathrm{p}<0.05$.

PU: The interaction effect of TIME*GROUP was significant (F2, $1=7.592 ; \mathrm{p}<0.012$; Partial Eta squared $=0.257)$. However, there was no significant difference between the two groups in terms of the mean PU in both the pre-test and posttest . There were no significant differences between the mean PU in the pre-test and post-test of the control group either. However, in the experimental group, there were significant differences between the mean PU in the pre-test and the post-test (pre-control $=2.25 \pm 00.86$, preexperimental $=2.41 \pm 00.79$, post-control $=2.08 \pm$ 1.08 , post-experimental $=2.50 \pm 00.52)($ Fig. 6$)$. 
SM: The interaction effect of TIME*GROUP was no significant $(F 2,1=0.401 ; \mathrm{p}>0.533$; Partial Eta squared $=0.018)$. There was no significant difference between the mean SM in both the pretest and post-test between the two groups. There were no significant differences between the mean $\mathrm{SM}$ in the pre-test and post-test of both the control and experimental groups either (pre-control = $2.33 \pm 00.49$, pre-experimental $=2.41 \pm 00.51$, post-control $=2.42 \pm 00.51$, post-experimental $=$ $2.75 \pm 00.45$ ) (Figure 7).

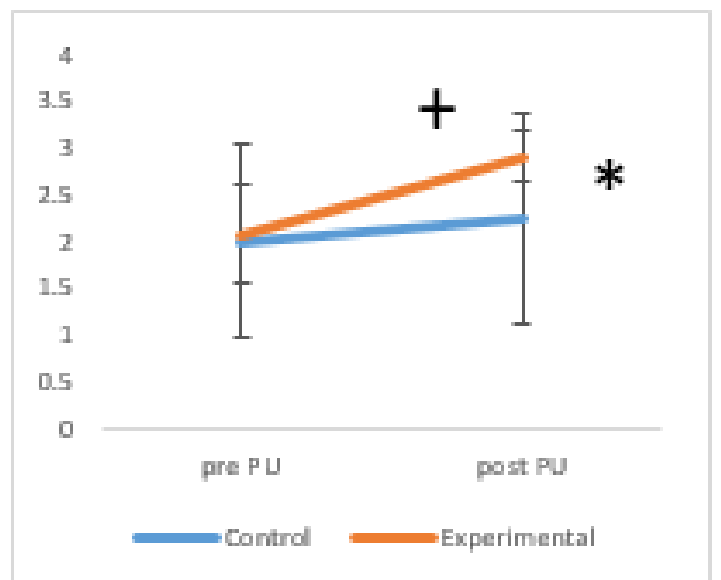

Figure 6. The Effects of Wrestling+ warm-up program on Trunk Stability Push Up (PU). *: interaction effect of GROUP*TIME is significant at $\mathrm{p}<0.05$. +: Significant difference with pre-test and post-test in the experimental and control groups at $\mathrm{p}<0.05$.

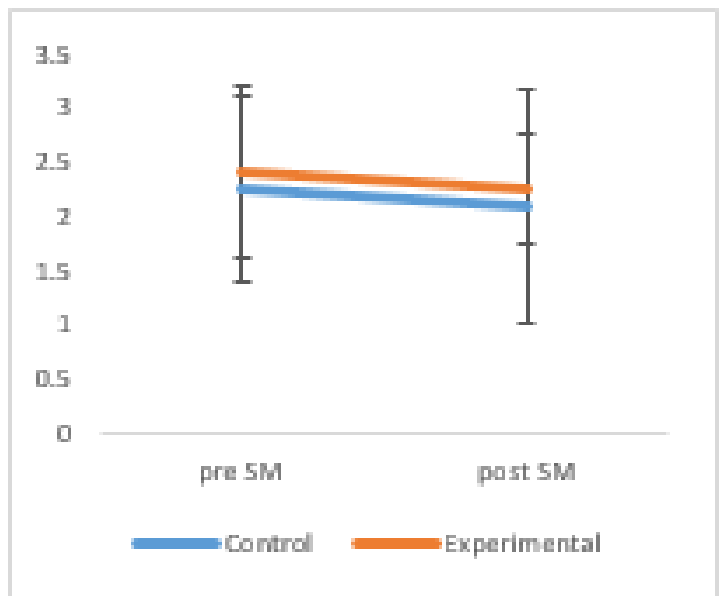

Figure 7. The Effects of Wrestling+ warm-up program on Shoulder Mobility (SM).

ASLR: The interaction effect of TIME*GROUP was not significant $(\mathrm{F} 2,1=0.297$; p $>0.591$; Partial Eta squared=0.013). There was no significant difference between the mean ASLR in the pre-test and post-test between the two groups. There were no significant differences between the mean ASLR in the pre-test and posttest of the control and experimental groups either (pre-control $=2.00 \pm 1.04$, pre-experimental $=$ $2.08 \pm 00.51$, post-control $=2.25 \pm 1.14$, postexperimental $=2.92 \pm 00.28$ ) (Figure 8).

RS: The interaction effect of TIME*GROUP was not significant $(F 2,1=1.00 ; p>0.328$; Partial Eta squared $=0.043$ ). There was no significant difference between the mean RS in the pre-test and post-test between the two groups. There were no significant differences either between the mean RS in the pre-test and post-test of the control and experimental groups (pre-control $=$ $2.00 \pm 00.00$, pre-experimental $=2.00 \pm 00.00$, post-control $=2.00 \pm 00.00$, post-experimental $=$ $2.08 \pm 00.28$ ) (Figure 9).

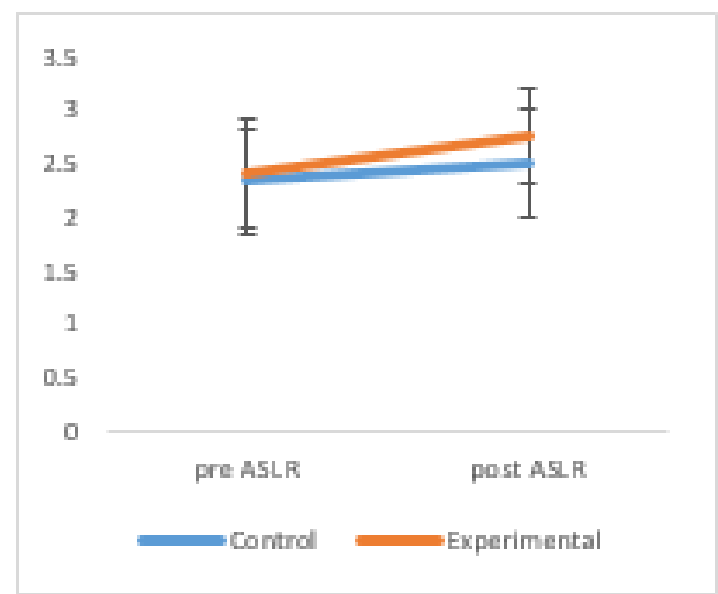

Figure 8. The Effects of Wrestling+ warm-up program on Active Straight Leg Raise (ASLR).

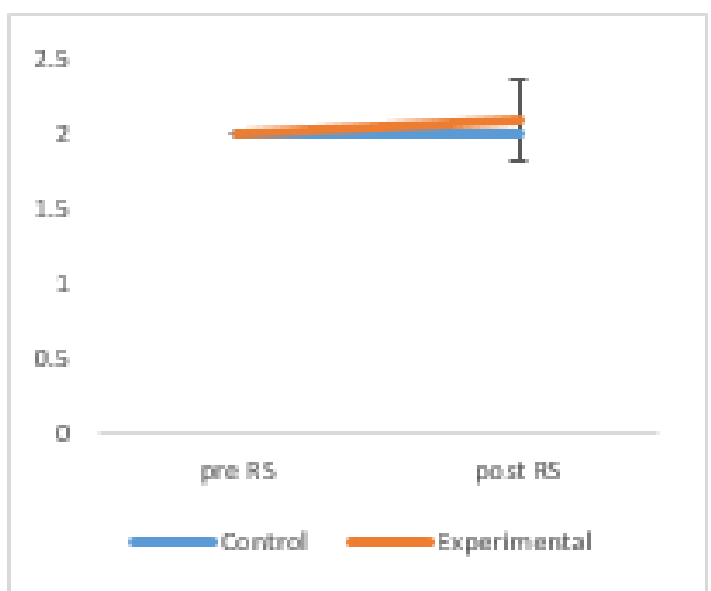

Figure 9. The Effects of Wrestling+ warm-up program on Rotary Stability $(R S)$. 
According to Table 1, the number of wrestlers subject to injury risks in the FMS test (score less than 14) after 12 weeks of training in the experimental group was reduced by $66.70 \%$. This reduction in the control group was only $16.7 \%$.

Table1. Changes in the number of wrestlers who had a score of 14 or less from pre- to post-test

\begin{tabular}{ccccc}
\hline Variable & Group & Time & 14 or less $(\mathrm{n})$ & $\mathbf{1 4}$ or less $(\boldsymbol{\%})$ \\
\hline \multirow{3}{*}{ FMS Total Score } & \multirow{2}{*}{ Control $(\mathrm{n}=12)$} & Pre test & 6 & $\mathbf{5 0 . 0 0}$ \\
\cline { 2 - 5 } & \multirow{2}{*}{ Experimental $(\mathrm{n}=12)$} & Post test & 4 & $\mathbf{3 3 . 3 0}$ \\
\cline { 2 - 5 } & & Pre test & 8 & $\mathbf{6 6 . 7 0}$ \\
\cline { 2 - 5 } & Post test & 0 & $\mathbf{0 0 . 0 0}$ \\
\hline
\end{tabular}

\section{DISCUSSION}

The results of this study indicated that the 12week "Wrestling+" warm-up program, significantly improved the Functional Movement Screen score of the cadet wrestlers. This program includes movements which have many common points with the Functional Movement Screen test movements. For example, there are movements such as squat on Bosu ball and push-up on Bosu ball in the "Wrestling+" warm-up program, a different form of which is seen in the functional movement screen test as DS and PU. Also, the existence of equilibrium movements such as the single-legged stand on the Bosu Ball, which are the main obstacle-stepping moves, can be a clear indication of the effectiveness of the Wrestling + warm-up program. Many studies have shown the positive impact of intervention exercises on Functional Movement Screen scores (17-19). The findings of Nemati et al. (2017) also showed that after completing the four weeks of FIFA +11 warm-up, the total Functional Movement Screen score in the experimental group significantly improved (20). Another important factor affecting the quality of performing the Functional Movement Screen movements is getting feedback from the coach when doing "Wrestling+" exercises. As "Wrestling+" warm-up program emphasized maintaining the correct posture and attention to the quality of exercising, and the experimental group constantly received feedback from the coach when doing the exercises, while the control group did not receive any corrective feedback in their exercises, this can also justify the difference between the post-test of the experimental and control groups. Klusemann et al. (2012) observed improved Functional Movement Screen test scores of junior basketball athletes by strength trainings who received coaching feedback, which was more greater compared to those without feedback from coaches (21). In this study, the movements of the Functional Movement Screen test were examined separately as discussed below. The results of this study showed that 12 weeks of "Wrestling+" warm-up program significantly improved DS, HS, and ILL scores in cadet wrestlers. Considering that strength, balance, and core stability were the main elements of the Wrestling + program involving movements such as squat on Bosu Ball (part II, exercise 8), standing single-leg on Bosu Ball, and performing the lateral flexion of the spine (part II, exercise 9), and each session was accompanied by corrective feedback, it seems reasonable to observe improved DS, HS, ILL scores in the Functional Movement Screen test. However, there was no significant improvement in the SM and ASLR scores of the cadet wrestlers. Since there is no static stretching exercise for the upper and lower limbs in the "Wrestling+" warm-up program, the insignificance of these two movements is already obvious. With regards to the impact of FIFA +11 exercises on the flexibility of soccer players, there was no significant improvement in the studies either, and the researchers attributed it to the absence of movements emphasizing static stretching in the FIFA + 11 program $(20,22)$. Due to the importance of flexibility in wrestling, to maintain flexibility, some stretching movements for upper and lower limbs can be done along with this program. A significant improvement was observed in the PU scores of the wrestlers. In the "Wrestling+" warm-up program, movements are done based on improving the core stability (part II, exercises 9 and 10), as well as movements contingent upon improving the strength of the upper body (part I, exercises 1, 2, 3 and 4). However, since one of the movements in this program is the push-up on the Bosu ball (part II, 
exercise 11), with emphasis on the modification of the motor pattern, the improvement of the PU scores of the wrestlers seems to be justified accordingly. No significant improvement was observed in RS scores. As stated above, core stability is a key element of "Wrestling+" warmup program. Regarding the mean scores of preand post-tests, there was a slight improvement in the post-test scores of this movement, but in general, no significant improvement was observed in the scores of this test. Due to the difficulty of this movement pattern, in order to achieve a perfect score, one should practice and perform this movement repeatedly, which was not the case in the "Wrestling+" warm-up program. The results of this study suggested that the 12weeks of "Wrestling+" warm-up program significantly reduced the number of subjects exposed to the injury threshold (14 or less) of the Functional Movement Screen test. Specifically, $66.7 \%$ of the subjects (8 wrestlers) in the experimental group and 50\% of the subjects (6 wrestlers) in the control group had a score of 14 or less in the pre-test. This number, after 12 weeks of "Wrestling+" warm-up program in the post test diminished to zero in the experimental group and to $33.30 \%$ in the control group (4 wrestlers). In other words, all subjects in the experimental group passed the injury threshold in the post test. Since the mean Functional Movement Screen scores of the experimental group was 14.03 and reached 18.25 in the post test, it seems that this improvement in the score of the Functional Movement Screen test significantly reduced the number of wrestlers at the injury threshold after 12 weeks of training. Bodden et al. (2015) observed a significant difference in the Functional Movement Screen test scores as well as the number of people over 14 in the experimental group compared to the control after 4 weeks of training in mixed martial arts athletes (17). In the study conducted by Nemati et al. (2017), the number of people above the injury threshold was $27 \%$ in pre-test, which reached $77 \%$ after 4 weeks of FIFA +11 training (20). The results of this study were consistent with the results of Bodden et al. (2015), Song et al. (2014), Kiesel et al. (2011), Klusemann et al. (2012), and Nemati et al. (2017).

\section{CONCLUSION}

The results of this study indicated that the "Wrestling+" warm-up program can improve the fundamental movement patterns, and finally it may prevent potential injuries. Although improvements were observed in the basic patterns by performing "Wrestling+" program, there is a need for further research with more subjects in this area due to the lack of research on "Wrestling+" program.

\section{APPLICABLE REMARKS}

- It is recommended that wrestlers and coaches use this new warm-up program before the specific training required.

- Coaches can use the Functional Movement Screen to identify wrestlers at risk of injury.

\section{REFERENCES}

1. Mirzaei B, Curby DG, Rahmani-Nia F, Moghadasi M. Physiological profile of elite Iranian junior freestyle wrestlers. The Journal of Strength \& Conditioning Research. 2009;23(8):2339-44. [DOI:10.1519/JSC.0b013e3181bb7350] [PMID]

2. Starosta SSW. Selected factors influencing the level of general fitness in elite Greco-Roman wrestlers. Journal of Human Kinetics volume. 2005;14:93-104.

3. Akbarnejad A, Sayyah M. Frequency of sports trauma in elite national level greco-roman wrestling competitions. Archives of trauma research. 2012;1(2):51. [DOI:10.5812/atr.6866] [PMID] [PMCID]

4. Halloran L. Wrestling injuries. Orthopaedic Nursing. 2008;27(3):189-92. [DOI:10.1097/01.NOR.0000320548.20611.16] [PMID]

5. Maffulli N, Longo UG, Gougoulias N, Loppini M, Denaro V. Long-term health outcomes of youth sports injuries. British Journal of Sports Medicine. 2010;44(1):21-5. [DOI:10.1136/bjsm.2009.069526] [PMID]

6. Shadgan B, Molnar S, Sikmic S, Chahi A. Wrestling Injuries During The 2016 Rio Olympic Games. Br J Sports Med. 2017;51(4):387-. [DOI:10.1136/bjsports-2016-097372.262]

7. Hewett TE, Pasque C, Heyl R, Wroble R. Wrestling injuries. Epidemiology of Pediatric Sports Injuries. 48: Karger Publishers; 2005. p. 152-78. [DOI:10.1159/000084288] [PMID] 
8. Gioftsidou A, Barbas I, Turlykhanov D, Podlivaev B, Tunnemann H, Sahmouratov Y, et al. Wrestling+ and New Structures for Youth Wrestling. International Journal of Wrestling Science. 2015;5(2):93-7. [DOI:10.1080/21615667.2015.1107663]

9. Soligard T, Myklebust G, Steffen K, Holme I, Silvers H, Bizzini M, et al. Comprehensive warm-up programme to prevent injuries in young female footballers: cluster randomised controlled trial. Bmj. 2008;337:a2469. [DOI:10.1136/bmj.a2469] [PMID] [PMCID]

10. Barbas I. GA. Wrestling+ for Youth Wrestler's. Wrestling Symposioym; in Las Vegas 2015

11. Bizzini M, Dvorak J. FIFA 11+: an effective programme to prevent football injuries in various player groups worldwide — a narrative review. Br J Sports Med. 2015;49(9):577-9. [DOI:10.1136/bjsports-2015-094765] [PMID] [PMCID]

12. Bahr R, Holme I. Risk factors for sports injuries - a methodological approach. British journal of sports medicine. 2003;37(5):384-92. [DOI:10.1136/bjsm.37.5.384] [PMID] [PMCID]

13. Wilkerson GB, Giles JL, Seibel DK. Prediction of core and lower extremity strains and sprains in collegiate football players: a preliminary study. Journal of athletic training. 2012;47(3):264-72. [DOI:10.4085/1062-6050-47.3.17] [PMID] [PMCID]

14. Cook G, Burton L, Hoogenboom B. Pre-participation screening: The use of fundamental movements as an assessment of function-Part 2. North American journal of sports physical therapy: NAJSPT. 2006;1(3):132. [PMID]

15. Cook G, Burton L, Hoogenboom B. Pre-participation screening: the use of fundamental movements as an assessment of function-part 1. North American journal of sports physical therapy: NAJSPT. 2006;1(2):62. [PMID]

16. Cook G. Movement: Functional movement systems: Screening, assessment, corrective strategies: On Target Publications; 2010.

17. Bodden JG, Needham RA, Chockalingam N. The effect of an intervention program on functional movement screen test scores in mixed martial arts athletes. The Journal of Strength \& Conditioning Research. 2015;29(1):219-25. [DOI:10.1519/JSC.0b013e3182a480bf] [PMID]

18. Kiesel K, Plisky P, Butler R. Functional movement test scores improve following a standardized off-season intervention program in professional football players. Scandinavian journal of medicine \& science in sports. 2011;21(2):287-92. [DOI:10.1111/j.1600-0838.2009.01038.x] [PMID]

19. Song H-S, Woo S-S, So W-Y, Kim K-J, Lee J, Kim J-Y. Effects of 16-week functional movement screen training program on strength and flexibility of elite high school baseball players. Journal of exercise rehabilitation. 2014;10(2):124. [DOI:10.12965/jer.140101] [PMID] [PMCID]

20. Nemati N, Norasteh AA, Alizadeh MH. The Effect of FIFA+ 11 Program on Functional Movement Screen Scores of Junior Soccer Players. Annals of Applied Sport Science. 2017;5(3):23-9. [DOI:10.29252/acadpub.aassjournal.5.3.23]

21. Klusemann MJ, Pyne DB, Fay TS, Drinkwater EJ. Online video-based resistance training improves the physical capacity of junior basketball athletes. The Journal of Strength \& Conditioning Research. 2012;26(10):2677-84. [DOI:10.1519/JSC.0b013e318241b021] [PMID]

22. Barengo NC, Meneses-Echávez JF, Ramírez-Vélez R, Cohen DD, Tovar G, Bautista JEC. The impact of the FIFA $11+$ training program on injury prevention in football players: a systematic review. International journal of environmental research and public health. 2014;11(11):11986-2000. [DOI:10.3390/ijerph111111986] [PMID] [PMCID] 